\title{
BMJ Open Curriculum framework for advanced practice nursing in sub-Saharan Africa: a multimethod study
}

\author{
Christmal Dela Christmals (D) ,,2 Susan J Armstrong ${ }^{1}$
}

To cite: Christmals CD, Armstrong SJ. Curriculum framework for advanced practice nursing in sub-Saharan Africa: a multimethod study. BMJ Open 2020;10:e035580. doi:10.1136/ bmjopen-2019-035580

- Prepublication history for this paper is available online. To view these files, please visit the journal online (http://dx.doi org/10.1136/bmjopen-2019035580).

Received 06 November 2019 Revised 30 April 2020 Accepted 05 May 2020
Check for updates

(c) Author(s) (or their employer(s)) 2020. Re-use permitted under CC BY-NC. No commercial re-use. See rights and permissions. Published by BMJ.

${ }^{1}$ Department of Nursing Education, School of Therapeutic Sciences, University of the Witwatersrand Faculty of Health Sciences, Johannesburg, Gauteng, South Africa

${ }^{2}$ SARChl Chair: Research on the Health Workforce for Equity and Quality, Centre for Health Policy, School of Public Health, University of the Witwatersrand, Johannesburg, Gauteng, South Africa

Correspondence to

Dr Christmal Dela Christmals; christmal.christmals@wits.ac.za

\section{ABSTRACT}

Objectives The implementation of advanced practice nursing (APN) programmes in sub-Saharan Africa (SSA) has been difficult due to lack of SSA-specific curriculum frameworks or benchmarks to guide institutions in developing and implementing APN programmes. A few APN programmes in SSA were benchmarked on western philosophy and materials, making local ownership and sustainability challenging. This paper presents an SSAspecific concept-based APN (Child Health Nurse Practitioner, CHNP) curriculum framework developed to guide institutions in developing relevant and responsive APN curricula in order to qualify CHNP and contribute to a decreased incidence of preventable deaths of children in the SSA region.

Design A sequential multimethod study design consisting of a scoping review, Delphi study, development of a framework by a curriculum team, and evaluation of the curriculum framework by faculty from 15 universities in SSA.

Setting This study included universities from East, West, Central and Southern Africa.

Participants The study included international multidisciplinary health professionals and curriculum development experts from 15 universities in 10 SSA countries.

Results A concept-based Advanced CHNP curriculum framework was developed. The faculty who evaluated the curriculum framework for applicability within their institutions and the SSA context unanimously stated that the framework is detailed, evidenced-based and could be adapted for other APN specialty areas.

Conclusion The Child Health Nurse Practitioner curriculum framework is comprehensive, context-specific and has the potential to respond to the special child healthcare needs of SSA. It is adaptable for other APN specialty programmes in SSA. Nursing leaders should lobby for funding and advocate for the introduction of the CHNP programme as a collaborative process between government, clinical services, communities and educational institutions.

\section{INTRODUCTION}

Advanced practice nursing (APN) legislation was established about seven decades ago in developed countries to respond to inequalities and poor access to healthcare among the rural and underserved populations. ${ }^{1-4}$ SubSaharan African (SSA) countries are struggling to develop and implement APN programmes even though they need APNs to respond to

\section{Strengths and limitations of this study}

The multimethod design allowed the researcher to choose and follow the processes of curriculum framework development.

- Multidisciplinary experts from East, West, Central and Southern Africa participated in this study giving it a wide coverage and multidisciplinary input.

- Though the use of nominal group technique in addition to the Delphi method would have been more appropriate for the evaluation of scoping review results and providing the content of the curricula, it was not possible due to the vastness of the context and funding limitations.

- The authors cannot guarantee that there will not be challenges in the implementation of the curriculum framework.

- Only 17 faculty from 10 sub-Saharan African countries responded to the evaluation questionnairethe authors cannot tell if the results would have been different should all the nursing institutions in sub-Saharan Africa responded.

needs of the excluded rural, underserved and vulnerable populations. ${ }^{5}$ The population of SSA is very poor, for instance, about $70 \%$ of the SSA population lives on less than US\$2.00 (R26.40) per day, while about $48 \%$ live on US\$1.25 (R16.27) per day. ${ }^{6}$ About 34 million school-aged children $(21.23 \%)$ are not in primary school. The poor child health services provided in SSA have led to the devastating rates of preventable child morbidity and mortality in the region. The impact of disease do not only affects the child at a younger age but also exposes the child to many health challenges in adulthood. APN programmes have proven to improve access to cost-effective quality healthcare for the rural, hard to reach, populations. $^{48}$

Sustainable Development Goal 3 demands that preventable deaths of newborn babies and children under the age of 5 years should be ended. ${ }^{9}$ Countries all over the world are expected to end preventable deaths with at most 12 neonatal deaths and 25 under 5 deaths 
per 1000 live births by 2030. Sustainable Development Goal 3 also requires that there must be universal coverage of quality healthcare, medicine and vaccines, and vital health services at an affordable cost. ${ }^{9}$

Botswana, Ghana, Kingdom of Eswatini, Malawi, Nigeria, Liberia, South Africa and Tanzania have all attempted the introduction of one form or another of APN. Difficulties experienced by these programmes include a lack of local ownership, inappropriate or no legislation to regulate and license the APNs, inability to sustain the programme and lack of context-specific (SSA-specific) APN benchmark curricula to guide the development of APN programmes. ${ }^{40-12}$ It is essential to have a context-specific APN (Child Health Nurse Practitioner, CHNP) curriculum framework for SSA. A formal curriculum consists of three components: the curriculum framework; course syllabi and textbooks; and other teaching and learning resources. The curriculum framework is a document that contains standards for a specific curriculum and indicates the context (natural, human and capital resources available) in which the curriculum developers develop curricula whereas the syllabus comprises the aim, content, outcomes and other information related to specific courses as prescribed in the curriculum framework. ${ }^{13}$ Stabback ${ }^{13}$ outlined the eight common elements of a standard curriculum framework thus: current context, educational policy statement, broad learning objectives and outcomes, structure of the educational system, structure of the curriculum content, standards of resources required for implementation, teaching methods and assessment and reporting methods. A wellestablished principle of the use of a curriculum framework is to leave the formulation of the syllabi and lesson plans to the institutions. This allows for flexibility and innovation at the lower level of curriculum implementation. ${ }^{14}$

\section{AIM}

This study sought to develop an APN (CHNP) curriculum framework to serve as an SSA context-specific guide for developing responsive APN curricula to qualify CHNP and contribute to decreased incidence of preventable deaths of children in the SSA region.

\section{METHOD}

This study applied a multimethod design. ${ }^{15}$ A literature review on child health and APN curriculum development in SSA was conducted. The findings of the review were subjected to expert review and inputs through an online expert Delphi. A seven-member curriculum committee was formed to develop concepts for the concept-based curriculum framework using the results from the review and the Delphi. The principal researcher then compiled the curriculum framework using the results from the preceding phases. The international multidisciplinary health experts who participated in the Delphi study were given the draft curriculum framework to review and state any deviations they identified in the framework from the data they provided. Seventeen curriculum development experts from 15 universities in 10 SSA countries evaluated the curriculum framework (figure 1). ${ }^{16}$

\section{The review}

Scoping reviews are either stand-alone or presystematic reviews that aim at exploring the breadth and depth

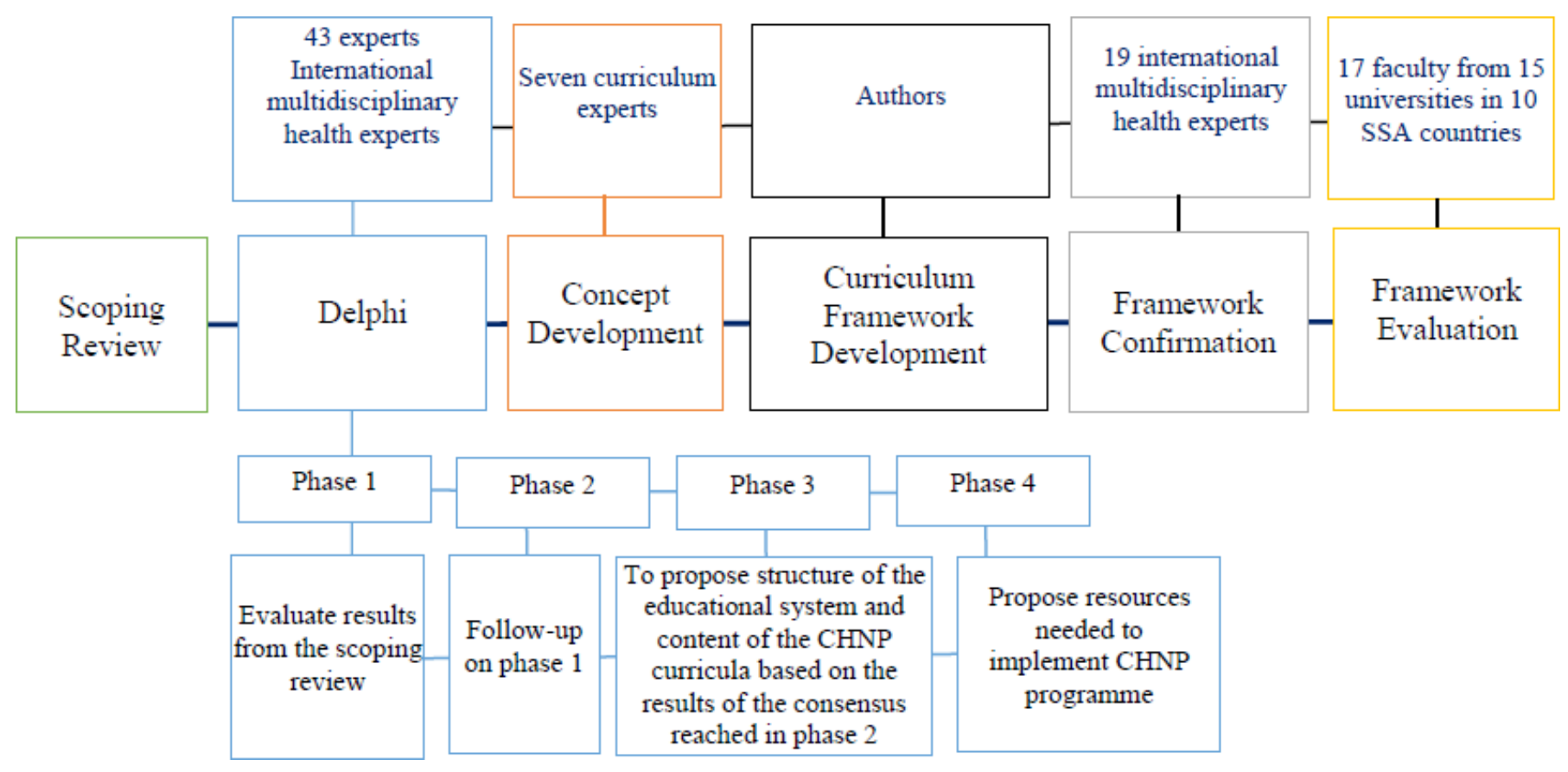

Figure 1 Summary of methods. Figure 1 presents the flow of the methods used in this study. The scoping review, followed by the Delphi, then concept development, curriculum framework development, confirmation and evaluation. CHNP, Child Health Nurse Practitioner; SSA, sub-Saharan Africa. 
(in-part) of a research area using both grey and peerreviewed literature. ${ }^{17-20}$ In this study, we applied the scoping review framework developed by Arksey and $\mathrm{O}^{\prime}$ Malley ${ }^{21}$ to establish the current state of APN and child health in SSA. ${ }^{4}$ The findings from the studies included in the review were synthesised according to the first three common elements of a curriculum framework, thus, current context, educational policy statement, statement of broad learning objectives and outcomes. ${ }^{13}$

\section{The Delphi}

The Delphi technique is a research method in which experts review documents in series in order to reach consensus on what best fits a particular situation or programme. ${ }^{22-24}$ The Delphi technique could take one to five or more stages depending on how quickly the expert committee reaches consensus. ${ }^{22} 232526$

In this study, the Delphi survey was conducted to contextualise the findings of the scoping review and to collect information from the multidisciplinary team on the structure of the educational system, content, teaching and learning methods, and resources needed to implement the CHNP programme in SSA.

\section{Delphi phases 1 and 2}

The Delphi questionnaire was developed from the results of the scoping review by the researchers, pretested by five master of science students from five different countries and reviewed by two child health nursing education experts for face and content validity. The questionnaire consisted of 80 Likert scale questions and 3 comment items. The questionnaire was divided into three sections: current context, educational policy statement and broad learning objectives. This study adopted a five-item Likert scale cum rating: strongly disagree (1); disagree (2); neutral (3); agree (4) and strongly agree (5). The first phases of the Delphi survey data were analysed using percentages; $80 \%$ agreement or disagreement was considered to be a consensus.

\section{Delphi phase 2}

Out of the 80 Likert scale questions in phase 1 , consensus was reached on 71 . The results of phase 1 were presented to the experts. The nine (9) questions on which consensus was not reached were rephrased and reposted for response by the experts. Consensus was then reached on the nine questions in phase 2 . The second phase of the Delphi saw attrition of eleven (11) experts, leaving 27 (21 nurses, five public health practitioners and one medical practitioner) expert participants.

\section{Delphi phases 3 and 4}

The last two phases were used to gather expert preferences on the last five common elements of a curriculum framework, thus, structure of the educational system, structure of the curriculum content, standard resources required for implementation, teaching methods and assessment methods. ${ }^{13}$ In phase three, the experts were asked to list topics, teaching and assessment methods for the six domains described under the broad learning objectives: (A) Nursing leadership and governance; (B) Quality practice; (C) Ethico-legal and professionalism; (D) Education and research; (E) Advanced child health nursing practice and (F) Attitudes and values.

In the last phase, the experts listed the resources necessary for the implementation of an APN programme in SSA. All 27 experts who completed phase 2 also completed phases 3 and 4, with a response rate of $100 \%$.

\section{Development of concepts}

The experts who participated in the Delphi preferred the concept-based curriculum to content, outcome or standard-based curricula because of its ability to provoke critical thinking and problem-solving abilities in students with minimum content. The curriculum committee was made up of seven purposively selected experts including five nursing curriculum experts, a paediatrician and a paediatric nurse: (1) a professor of nursing education with expertise in curriculum development across the globe especially in the USA, Haiti, Ghana, Uganda, eSwatini and Liberia; (2) a senior lecturer, nurse educator and head of an inter-professional simulation laboratory; (3) a nurse educator, former registrar of a nursing council, currently working as a for a ministry of health(employer); (4) a child health nurse, a lecturer and a consultant for a specialist children's hospital; (5) a nursing educator, with experience in concept-based curriculum development, nursing regulation, leadership and healthcare quality improvement; (6) a paediatrician, fellow of the College of Paediatricians of South Africa and (7) an APN researcher, a nurse educator. The principal author facilitated the process. Twenty-two concepts were developed using instructions for selecting concepts for a conceptbased CHNP curriculum framework developed by the researcher to guide the curriculum committee. This was a 12-page document comprising the overview of the curriculum structure, knowledge domains from the scoping review, results of the Delphi, the stages of developing a concept-based curriculum and a graphical guide for selecting concepts and exemplars for a CHNP curriculum synthesised from Ignatavicius ${ }^{, 27} 12$-steps of developing a concept-based curriculum. The concepts were analysed by the team using the components of concept analysis outlined by Johnston. ${ }^{28} 29$

\section{Framework development, confirmation and evaluation}

The principal researcher compiled the framework consisting of the eight common components of a curriculum framework listed in section 1.0. The draft curriculum framework was sent via email to the 27 international multidisciplinary health experts who participated in the last phase of the Delphi. Nineteen (19) of participants who responded stated that the framework accurately represented the data they provided. After the confirmation, 17 curriculum development experts from 15 universities in 10 SSA countries were purposively selected to evaluate the curriculum framework. The participants 
were included if they were faculty of a Department or School of Nursing in SSA and had extensive research or practice experience in nursing curriculum development. Comments from the curriculum development experts were used to finalise the curriculum framework.

\section{Patient and public involvement}

No patient involved.

\section{RESULTS}

\section{Current context}

Current context refers to the socioeconomic setting within which an APN (CHNP) policy is made and the programme implemented. The population of SSA is very poor, for instance, about $70 \%$ of the SSA population is living on less than US\$2.00 (R26.40) per day, while about $48 \%$ live on US $\$ 1.25$ (R16.27) per day. ${ }^{67}$ About 34 million school-aged children (21.23\%) are not in primary school.

The poor child health services provided in SSA have led to the devastating rates of preventable child morbidity and mortality in the region. The impact of disease not only affects the child at a younger age but also exposes the children to many health challenges in adulthood. APN programmes have been shown to improve access to cost-effective quality healthcare for the rural, hard to reach, populations. ${ }^{48}$

Even though some institutions and countries within SSA have shown interest in APN programmes, they lack contextual benchmarks and role models to guide the development and implementation of APN programmes. ${ }^{48}$

\section{The educational policy statement}

This describes the goals of governments and institutions for the APN (CHNP) programme. ${ }^{13}$ Educational policy is influenced by local health needs and international policy. Sustainable Development Goal 3 demands that preventable deaths of new-born babies and children under the age of 5 years should be ended. ${ }^{9}$ Countries all over the world are expected to end preventable deaths with at most 12 neonatal deaths and 25 under 5 deaths per 1000 live births by 2030. Sustainable Development Goal 3 also requires that there must be universal coverage of quality healthcare, medicine and vaccines, and vital health services at an affordable cost. ${ }^{9}$ The goal of the APN programme is to train adequate numbers of APN who are willing to provide patient-centred care for the rural populations of SSA. The expert team unanimously asserted that there must be at least one CHNP who is competent in the integrated management of childhood diseases and resuscitation of babies at every Primary Health Care clinic.

\section{Broad learning objectives and outcomes}

The broad learning objectives and outcomes stipulate what the APN should know and be able to do when he or she completes the programme. ${ }^{13}$ The outcomes are expressed in a range of domains, including knowledge, understanding, skills, competencies, values and attitudes. The CHNP should be knowledgeable, have competent skills and attitudes in the knowledge domains listed in table 1 .

\section{Structure of the educational system}

The structure of the educational system stipulates the general educational system within which the APN programme will be implemented as outlined in table 2 . This section of the curriculum framework specifies the duration of the programme, number of school weeks in an academic year, notional hours and associated credits for the APN (CHNP) programme.

\section{Structure of the curriculum content}

The structure of curriculum content defines the concepts for the CHNP programme. The concepts are presented with definition, scope, characteristic features, attributes, exemplars and interrelated concepts presented in table 3 adapted from Christmals $e t a l .{ }^{8}$ The modules developed in this study are presented in figure 2.

\begin{tabular}{|c|c|}
\hline Domain & Brief description \\
\hline Domain A: Nursing Leadership and Governance & $\begin{array}{l}\text { The key responsibilities of APNs in their setting are healthcare governance, leadership, } \\
\text { management, advocacy and resource management. }\end{array}$ \\
\hline Domain B: Quality Practice & $\begin{array}{l}\text { This domain covers issues of quality in healthcare delivery and continuous professiona } \\
\text { development. }\end{array}$ \\
\hline Domain C: Ethicolegal Practice and Professionalism & $\begin{array}{l}\text { This domain covers the ethos of professional practice. It also refers to all the legal } \\
\text { aspects of the Advanced Practice Nurse's practice. }\end{array}$ \\
\hline Domain D: Education and Research & This domain covers clinical teaching, community education and research. \\
\hline Domain E: Advanced Child Health Nursing Practice & $\begin{array}{l}\text { Advanced Child Health Nurse Practitioners are expected to conduct an assessment } \\
\text { (history taking, physical examination, request and interpret laboratory and imaging } \\
\text { studies), diagnose children, prescribe treatment (pharmacological and non- } \\
\text { pharmacological), admit, discharge, refer and comprehensively manage patients in } \\
\text { their practice settings. }\end{array}$ \\
\hline Domain F: Attitudes and Values & This domain deals with patient and family centred care and cultural sensitivity. \\
\hline
\end{tabular}

APN, advanced practice nursing. 


\begin{tabular}{ll}
\hline Table 2 & Structure of the educational system \\
\hline Variable & Description \\
\hline $\begin{array}{l}\text { Level } \\
\text { Ontological orientation }\end{array}$ & $\begin{array}{l}\text { Master's level (SAQA NQF level 9) } \\
\text { approaches }\end{array}$ \\
\hline $\begin{array}{l}\text { Epistemological } \\
\text { orientation }\end{array}$ & Concept-based curriculum/learning \\
\hline $\begin{array}{l}\text { Total credit } \\
\text { No of years }\end{array}$ & $\begin{array}{l}360 \text { credits (180 credits per year) } \\
\text { No of weeks full-time }\end{array}$ \\
\hline No of hours per week & 40 weeks a year \\
\hline Total clinical hours & $\begin{array}{l}\text { 800-1000 hours a week } \\
\text { Internship }\end{array}$ \\
\hline
\end{tabular}

SAQA NQF, South African Qualification Authority National Qualification Framework. $^{39}$

\section{Standards of resources required for implementation}

Standards of resources describe the level of lecturer qualifications, workload per lecturer, student qualifications and number per class, materials (textbooks, computers and other equipment) and facilities (classrooms, furniture, fittings).

\section{Lecturer qualifications}

Nursing lecturers are expected to have a $\mathrm{PhD}$ in nursing. Consideration is given to a master of nursing (coursework and research components). Non-nurse lecturers are also expected to have obtained $\mathrm{PhD}$ in a specialist field. Consideration is given to a Master of Medicine and equivalent qualification if there are no PhD holders. All lecturers in the CHNP programme should have at least a Diploma in Health Science Education.

\section{Student qualifications and resources}

A 4-year degree in nursing with a minimum of $60 \%$ cumulative average mark is required for admission into the CHNP programme. Two years' minimum clinical practice after Community/National/Youth Service or internship is the prerequisite clinical practice for gaining admission into the CHNP programme. Mathematics, computing skills and English/French language skills are required for admission into the CHNP programme. Paediatric Nursing, Anatomy, Physiology, Psychology, Sociology, Pharmacology, Microbiology, Community Health Nursing, Family Health Nursing, Communicative Skills, Research Methods and Fundamentals of Nursing are courses the candidate should have taken in an undergraduate programme to qualify for the CHNP programme. Students are expected to have personal materials such as a laptop computer, prescribed textbooks, and a diagnostic set to promote effective learning.

\section{Library resources}

The students should have access to textbooks, computers, internet services, online learning platform (eg, Sakai,
Moodle), subscription to research database and online books.

\section{Classroom resources}

Classroom resources to support the implementation of the programme include liquid-crystal display projector, comfortable tables and chairs for students, good ventilation and temperature regulation system, chalkboard and chalk, white/marker board and markers, good lighting and good ventilation.

\section{Teacher-student ratio}

A lecturer student ratio between the ranges of 1:7 to 1:14 is desirable.

\section{Teaching methods}

Teaching methods describe the range of teaching approaches that might be employed in the implementation of the framework. Experiential learning and problembased learning, which are adult education oriented, are to be implemented to inculcate the level of critical thinking, problem-solving and ability to apply concepts to general to situations. The expert team also proposed small group sessions, self-study and blended learning methods.

\section{Assessment and reporting methods}

Assessment and reporting methods describe the modes of assessment, pass marks and how the student achievements are awarded or certified. Assessment should seek to determine the CHNP's critical thinking, problemsolving and ability to apply concepts to general situations in the healthcare setting and community that are served. Objective Structured Clinical Examination, written tests and examinations, viva-voce and take-home assessments were proposed by the expert team.

\section{Other elements}

Other elements of this curriculum framework in addition to the eight (8) elements of a curriculum framework outlined by Stabback ${ }^{13}$ include clinical practice, internship, licensure and continuous professional development (CPD), and adoption and adaptation instructions.

\section{Clinical training}

Clinical training describes the mode of clinical training (clinical practice for learning and role-taking) by the student enrolled in the CHNP programme. Simulation laboratory, clinical placement facilities, anatomical models, clinical mentors, simulators, clinical supervisors, resuscitation equipment, diagnostic sets, personal protective equipment and a qualified skills laboratory technician are materials and resources needed for successful clinical training. Between 800 and 1000 hours of clinical placement for learning and role-taking is prescribed for the 2-year training programme.

Internship

A 1-year internship under the supervision of a paediatrician, if available, is recommended. 


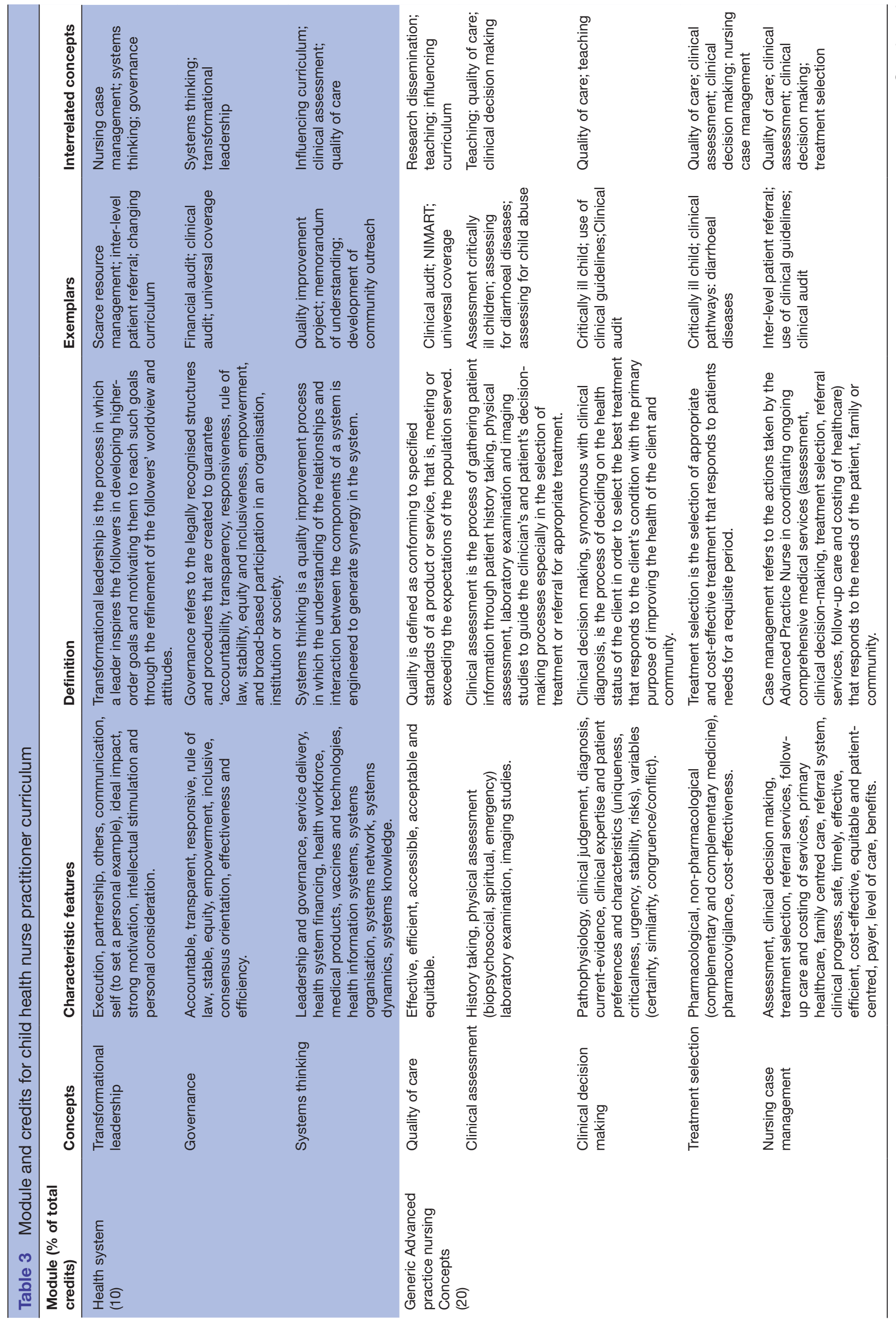

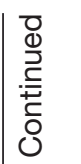




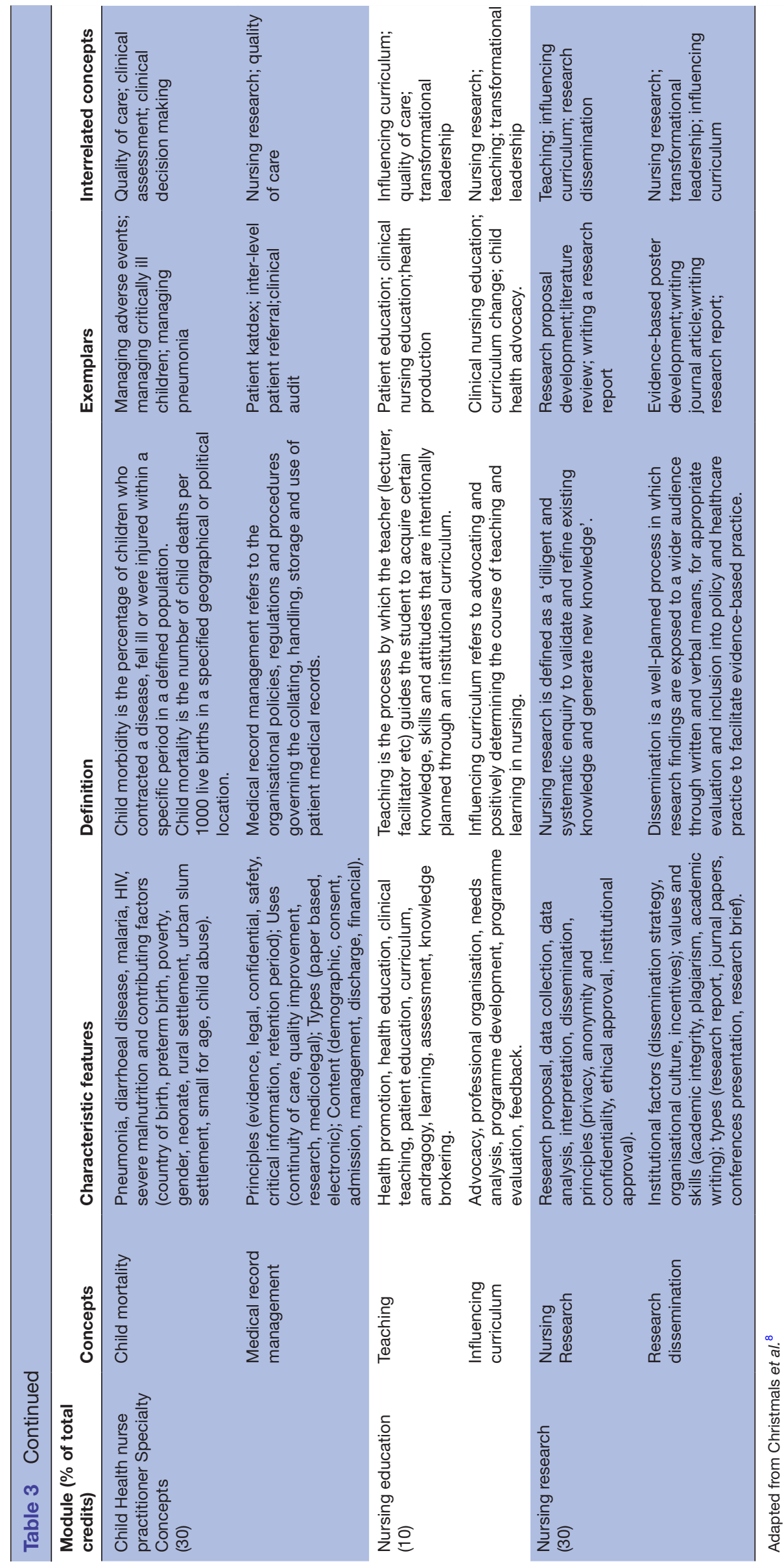

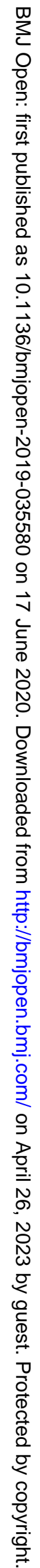


PROGRAMME OUTCOME: To produce competent Advanced Practice Nurses who will produce evidence-based,
culturally sensitive and cost-effective quality child health care to the underserved populations in sub-Saharan Africa. culturally sensitive and cost-effective quality child health care to the underserved populations in sub-Saharan Africa.

\begin{tabular}{|c|c|c|c|c|}
\hline HEALTH SYSTEM & $\begin{array}{l}\text { GENERIC APN } \\
\text { CONCEPTS }\end{array}$ & $\begin{array}{l}\text { CHNP SPECIALTY } \\
\text { CONCEPTS }\end{array}$ & $\begin{array}{l}\text { NURSING } \\
\text { EDUCATION }\end{array}$ & $\begin{array}{l}\text { NURSING } \\
\text { RESEARCH }\end{array}$ \\
\hline \begin{tabular}{c|} 
Transformational \\
leadership, governance, \\
systems thinking
\end{tabular} & $\begin{array}{l}\text { Quality of care, clinical } \\
\text { assessment, clinical } \\
\text { decision making, treatment } \\
\text { selection, medical record } \\
\text { management }\end{array}$ & $\begin{array}{l}\text { Nursing case } \\
\text { management, child } \\
\text { mortality }\end{array}$ & $\begin{array}{l}\text { Teaching, influencing } \\
\text { curriculum }\end{array}$ & $\begin{array}{l}\text { Nursing research, } \\
\text { research dissemination }\end{array}$ \\
\hline $\begin{array}{l}\text { The APN will be able to } \\
\text { comprehend national and } \\
\text { international health } \\
\text { systems and their } \\
\text { influence on child health } \\
\text { nursing and be able to } \\
\text { lead and transform the } \\
\text { health system at the local } \\
\text { level in order to facilitate } \\
\text { the provision of evidence- } \\
\text { based, culturally sensitive } \\
\text { and cost-effective quality } \\
\text { child health care to the } \\
\text { underserved populations } \\
\text { in sub-Saharan Africa }\end{array}$ & $\begin{array}{l}\text { The CHNP will be able to } \\
\text { acquire knowledge, } \\
\text { competent skills and attitudes } \\
\text { need to provide evidence- } \\
\text { based, culturally sensitive } \\
\text { and cost-effective quality } \\
\text { child health care provided for } \\
\text { the underserved populations } \\
\text { in sub-Saharan Africa } \\
\text { (assess, diagnose, manage } \\
\text { and record) }\end{array}$ & $\begin{array}{l}\text { The CHNP will be able to } \\
\text { plan, execute and evaluate } \\
\text { evidence-based, culturally } \\
\text { sensitive and cost-effective } \\
\text { quality child health care to } \\
\text { the underserved } \\
\text { populations in sub-Saharan } \\
\text { Africa with the aim of } \\
\text { reducing child mortality } \\
\text { and improving other } \\
\text { healthcare indices }\end{array}$ & $\begin{array}{l}\text { The CHNP will be able to } \\
\text { impart evidence-based, } \\
\text { culturally sensitive health } \\
\text { information to the child, } \\
\text { family and community in } \\
\text { order to promote, restore or } \\
\text { maintain their health status } \\
\text { and to inculcate the } \\
\text { lnowledge, attitudes and } \\
\text { behaviours necessary to } \\
\text { provide evidence-based, } \\
\text { culturally sensitive cost- } \\
\text { effective quality child health } \\
\text { care to the underserved } \\
\text { populations in sub-Saharan } \\
\text { Affica into nursing students } \\
\text { through clinical teaching. }\end{array}$ & $\begin{array}{l}\text { The CHNP will be able to } \\
\text { propose, conduct research } \\
\text { and synthesize research } \\
\text { findings in order to provide } \\
\text { evidence-based, culturally } \\
\text { sensitive and cost-effective } \\
\text { quality child health care to } \\
\text { the underserved } \\
\text { populations in sub-Saharan } \\
\text { Africa }\end{array}$ \\
\hline
\end{tabular}

Figure 2 Structure of the curriculum content. The content of the framework is presented in five modules as presented in table 2. The modules consist of health systems generic APN concepts, CHNP specialty concepts, nursing education and nursing research. APN, advanced practice nursing; CHNP, child health nurse practitioner.

\section{Licensure and CPD}

Licensing of the APN should be done at the discretion of the nursing council under which he or she is registered.

\section{Adoption and adaptation of the CHNP curriculum framework}

The framework should be adopted and adapted to suit each country in SSA.

Changes to this curriculum framework could affect the context, aim, knowledge domains, resources and concepts. Due to the expectations of the APN and the aim of having the APN programme locally relevant and internationally competitive, changes to the level of training and number of years of training are not advised. Resistance from the medical profession, limited human and fiscal resources and lack of political will are some of the challenges that need to be surmounted in the implementation of this programme.

\section{Confirmation and evaluation of the curriculum framework Confirmation}

The 27 international multidisciplinary health experts who took part in the last phase of the Delphi study were given the draft curriculum framework to review and state any deviations they identified in the framework from the data they provided. Nineteen (19) of the 27 participants responded to the confirmation questionnaire. They all stated that the curriculum framework accurately represented the data they provided for the study.

\section{Evaluation}

Fifty (50) faculty from 38 institutions in 15 SSA countries (Botswana, Ethiopia, Ghana, Kenya, Liberia, Malawi,
Nigeria, Lesotho, South Africa, Rwanda, Swaziland, Tanzania, Uganda, Zambia and Zimbabwe) were invited to participate. Seventeen faculty from fifteen nursing education institutions in ten SSA countries (Ghana 2, Botswana 1, Swaziland 2, South Africa 1, Nigeria 2, Rwanda 2, Uganda 1, Kenya 2, Malawi 1 and Zambia 1) responded to the evaluation questionnaire before the close of the study. One response was incomplete and was excluded from the study, leaving 16 . The 16 curriculum development experts stated the framework was applicable in SSA. Some participants said:

It is applicable because the framework responds to the needs of the country. However, it will require a change in policy especially in regard to the scope of nurses.- Rwanda 1

There is an adequate, easy-to-understand description of the current context, educational policy statement, statement of broad learning objectives, the structure of the Child Health Nurse Practitioner programme.Nigeria 1

It is evidence-based and issues discussed affect us as a country. The issues of high neonatal, infant and child mortality-SDG 3. There is a need for our country to train nurses who will provide quality care to the children as paediatricians do not spend a long time with the children. Our country has $79 \%$ of the population residing in rural areas.- Swaziland 1

The participants also believed that the advanced CHNP curriculum framework could be adapted for other APN 
specialties. A faculty stated that the guidelines provided for the adoption and adaptation of the curriculum framework will be very helpful for her institution and country. Three faculty indicated that the curriculum framework will be easily adopted if it is adapted using countryspecific burden of diseases. Other recommendations include disseminating the framework on compact disks and other electronic formats to make it accessible to the stakeholders of nursing in SSA. These institutions are major gatekeepers for nursing education programmes in every country. The ability of this programme to make any impact in SSA will depend, largely, on their approval.

\section{DISCUSSION}

This is the first postgraduate level concept-based curriculum framework to be developed; it was laborious trying to determine how many concepts were sufficient and which ones to include. The difficulty in determining how many concepts to be included in the curriculum was also reported by Giddens $e t a P^{30}$ in their state-wide undergraduate concept-based curriculum development.

The APNs are expected to practice extended roles that involve comprehensive assessment and diagnosing and management of illness and diseases. This requires extensive knowledge of the disease process and the essential skills to function effectively. The concepts for advanced nursing practice were carefully selected to equip the APN with the needed skills in clinical practice. Fifty per cent of the concepts presented the advanced nursing practice specialty area. The remaining concepts that were included were specific to the content in research, education and health systems, which implies the need for vital knowledge, skills and attitudes by the APN to function effectively.

For the APNs to be competent in evidence-based practice, they need to be able to generate evidence and be competent in utilising such evidence. The APN will be expected to do clinical teaching for nursing programmes and to educate the patient in the clinical setting. To do that, the concepts of nursing education are necessary. The APN will acquire knowledge, skills and attitudes to teach students and clients effectively in hospital settings. The health system is the larger context within which the APN will practice. To be able to function within the confines of the law and to produce positive effects in practice, the APN must understand the health system, the players in it and their demands. Three concepts were included under health systems to guide the APN understanding of the health systems. He or she is envisaged as the leader at the community healthcare level, therefore, leadership and governance skills are important for the APN's practice.

The knowledge domains defined in this study are not significantly different from the competencies of APN prescribed by the Nursing and Midwifery Board of Ireland. ${ }^{31}$ They are also in alignment with the course structure of the Nurse Practitioner programme implemented by the University of British Columbia, ${ }^{32}$ with the exception that the University of British Columbia's programme emphasises pathophysiology and pharmacology. The Royal College of Nursing ${ }^{33}$ also emphasised pathophysiology and pharmacology. All other components are the same, with the exception that this curriculum is concept-based and does not encourage the emphasis on content, rather concepts such as decision making and treatment selection, which includes pathophysiology and pharmacology.

In a study to explore the fundamental aspects of APN in aesthetic medicine, Greveson ${ }^{34}$ reported 'developing a nurse-led service; patient assessment and decision making; consultation skills; treatment selection; non-medical prescribing; insurance and record-keeping; audit and research and CPD' as the components of aesthetic medicine for APN. These components are consistent with the concepts reported in this study, with a few nomenclature differences.

The concepts developed in this study are of higher thinking and problem solving than those developed for undergraduate nursing by Giddens, as the APN are expected to practice at a higher level than the graduate nurses-advanced assessment, diagnosing, prescribing and management of care. ${ }^{35}$

The structure of the education system reported in this study is supported by the APN programmes implemented in the USA, UK, Canada and other parts of the world. The differences are the number of credits for the programme, type of curriculum and context in which the programme is being implemented. Differences in credits are a result of the different credit systems used in different jurisdictions. ${ }^{132}$ The structure of the curriculum content has been organised into modules which are made up of concepts. This is a unique way of curriculum content organisation, as the concept-based curricula reported by other authors ${ }^{27} 3637$ were organised into courses. The modular structure of curriculum best suits postgraduate education and reformed higher education from its traditional subject, course, semester nature. ${ }^{38}$ The concept-based epistemological perspective of this curriculum is essential in reducing the content of the APN curriculum while allowing the CHNP to acquire the knowledge, skills and attitudes needed to function at a competent level in critical thinking and problem-solving. Less content will also give the CHNPs enough time for clinical practice.

Though the authors put in measures to ensure the rigour in this study, the study is not without limitations. Though the use of a nominal group technique in addition to the Delphi method would have been more appropriate for the evaluation of scoping review results and providing the content of the curricula, it was not possible due to the vastness of the context and funding limitations. Also, only 17 faculty from 10 SSA countries responded to the evaluation questionnaire. The authors cannot tell if the results would have been different if all the nursing institutions in SSA evaluated the framework for applicability. Also, the authors cannot guarantee that there will not be challenges in the implementation of the curriculum framework. 


\section{CONCLUSION}

The Child Health Nursing Practitioner curriculum framework is comprehensive, context-specific, has the potential to respond to the special child healthcare needs of SSA and is adaptable for other APN specialty programmes in SSA. The nursing leadership should lobby and professionally advocate for funding and introduction of the CHNP programme as a collaborative process between government, clinical services, public and educational institutions; and propose how this can be done. Child mortality is a global phenomenon. The CHNP could be adapted for other contexts in which human resources for primary healthcare for children is lacking.

Acknowledgements We wish to acknowledge: Professor Janet Gross, Mr Kizito Aidam and Lesley Fletcher for editing this work; and Professor Laetitia Rispel for the support provided during the manuscript writing phase. Special thanks to Professor Gerda Reitsma and the Centre for Health Professions Education, NorthWest University for their support during the revison of this manuscript.

Contributors Both authors, CDC and SJA were involved in study conceptualisation, literature review, data collection, data analysis, result interpretation and manuscript writing.

Funding This study was self-funded.

Competing interests None declared.

Patient consent for publication Not required.

Ethics approval This study was approved by the Faculty of Health Sciences Human Research Ethics Committee (M160632), University of the Witwatersrand and the Noguchi Memorial Institute of Medical Research Institutional Review Board, the University of Ghana (009/16-17).

Provenance and peer review Not commissioned; externally peer reviewed.

Data availability statement Data are available in a public, open access repository. Data collected for this study has been deposited in the Mendeley database: Christmals, Christmal (2019), 'Dataset_Concepts for Advanced Practice Nursing Curriculum in Sub-Saharan Africa', Mendeley Data, V.1 https://data.mendeley.com/ datasets/2kmpt2wg9s/1.

Open access This is an open access article distributed in accordance with the Creative Commons Attribution Non Commercial (CC BY-NC 4.0) license, which permits others to distribute, remix, adapt, build upon this work non-commercially, and license their derivative works on different terms, provided the original work is properly cited, appropriate credit is given, any changes made indicated, and the use is non-commercial. See: http://creativecommons.org/licenses/by-nc/4.0/.

ORCID iD

Christmal Dela Christmals http://orcid.org/0000-0003-1811-0008

\section{REFERENCES}

1 Duffield C, Gardner G, Chang AM, et al. Advanced nursing practice: a global perspective. Collegian 2009;16:55-62.

2 Sheer B, Wong FKY. The development of advanced nursing practice globally. J Nurs Scholarsh 2008;40:204-11.

3 Maier CB, Barnes H, Aiken LH, et al. Descriptive, cross-country analysis of the nurse practitioner workforce in six countries: size, growth, physician substitution potential. BMJ Open 2016;6:e011901.

4 Christmals CD, Armstrong SJ. The essence, opportunities and threats to advanced practice nursing in sub-Saharan Africa: a scoping review. Heliyon 2019;5:e02531.

5 Geyer N, Christmals C. Advanced practice nursing in Africa. In: Hassmiller SB, Pulcini J, eds. Advanced practice nursing leadership: a global perspective. Springer, 2020: 63-76. https://link.springer. com/chapter/

6 ECOSOC. Progress towards the sustainable development goals: report of the Secretary General, 2017.

7 Liu L, Oza S, Hogan D, et al. Global, regional, and national causes of under-5 mortality in $2000-15$ : an updated systematic analysis with implications for the Sustainable Development Goals. Lancet 2016;2016:3027-35.
8 Christmals CD, Crous L, Armstrong SJ. The development of concepts for a Concept-Based advanced practice nursing (child health nurse practitioner) curriculum for sub-Saharan Africa. Int $J$ Caring Sci2019;12:1410-22.

9 World Health Organization. Sustainable development goals (SDGs) SDG 3: ensure healthy lives and promote wellbeing for all at all ages. WHO, 2016: 1-2.

10 Anathan J. Family nurse practitioners: essential to Eswatini's Health. 1. Seed Global Health, 2018. https://seedglobalhealth.org/familynurse-practitioners-essential-to-eswatinis-health/\#.XtNtRFQzblW

11 Mtuya CC, Blood-Siegfried J. Development of the $n p$ role in Tanzania. Rotterdam, Netherlands: 10th ICN NP/APN conference, 2018: 1-20. http://www.npapn2018.com/wp-content/uploads/2018/09/88Development-of-the-nurse-practitioner-role-in-Tanzania.pdf

12 Nursing \& Midwifery Council, Nurs Midwifery Counc Ghana. Nurse practitioners, 2014. Available: http://nmcgh.org/t3f/en/traininginstitutions/80-professionals/13-workshop-for-nurse-practitioners [Accessed 19 May 2019].

13 Stabback P. Guidelines for constructing a curriculum framework for basic education Kigali, 2007. Available: http://www.ibe.unesco.org/ fileadmin/user_upload/COPs/Pages_documents/Resource_Packs/ TTCD/sitemap/resources/3_1_1_P_ENG.pdf

14 Parsons J, Beauchamp L. From knowledge to action: shaping the future of curriculum development in Alberta, 2012. Available: https:// open.alberta.ca/dataset/bc0bd7df-2bfe-4b8b-8af0-db19b17a7721/ resource/5f11d83e-3074-408b-bff7-bcc27987864a/download/ 5976960-2012-From-Knowledge-Action-Curriculum-DevelopmentAlberta.pdf [Accessed 27 Oct 2017].

15 Hunter A, Brewer JD. Designing multimethod research: the oxford handbook of multimethod and mixed methods research inquiry. 2015. Oxford:Oxford University Press, 2015.

16 Christmals CD. Dataset_concepts for advanced practice nursing curriculum in sub-Saharan Africa, 2019. Available: https://data. mendeley.com/datasets/2kmpt2wg9s/1 [Accessed 6 Nov 2019].

17 Wach E, Ward R, Jacimovic R. Learning about qualitative document analysis. Inst Dev Stud Pap Br 132013 2008:1-10.

18 Armstrong R, Hall BJ, Doyle J, et al. 'Scoping the scope' of a cochrane review. J Public Health 2011;33:147-50.

19 Stoffels M, Peerdeman SM, Daelmans HEM, et al. Protocol for a scoping review on the conceptualisation of learning in undergraduate clinical nursing practice. BMJ Open 2019;9:e024360.

20 Tricco AC, Lillie E, Zarin W, et al. PRISMA extension for scoping reviews (PRISMA-ScR): checklist and explanation. Ann Intern Med 2018;169:467.

21 Arksey H, O'Malley L. Scoping studies: towards a methodological framework. Int J Soc Res Methodol 2005;8:19-32.

22 Hsu C, Sandford B. The delphi technique: making sense of consensus. Pract Assessment. Res Eval 2007;12:1-8.

23 Meshkat B, Cowman S, Gethin G, et al. Using an e-Delphi technique in achieving consensus across disciplines for developing best practice in day surgery in Ireland. J Hosp Adm 2014;3:1-8.

24 Myezwa H. Mainstreaming HIV / AIDS in physiotherapy education and practice. University of the Witwatersrand, 2009. http:// wiredspace.wits.ac.za/handle/10539/7165

25 Deane MODekker K, Davies P, et al. A Delphi survey of best practice occupational therapy for Parkinson's disease in the United Kingdom. Br J Occup Ther 2003;66:247-54.

26 Raine S. Defining the Bobath concept using the Delphi technique. Physiother Res Int 2006;11:4-13.

27 Ignatavicius DD. Teaching and learning in a concept-based nursing curriculum : a how-to best practice approach, 2017. Available: https://books.google.co.za/books/about/Teaching_and_Learning_in a_Concept_Based.html?id=RCpdnQAACAAJ\&redir_esc $=y$ [Accessed 24 Sep 2017].

28 Johnston D. Navigating the move to concept-based curriculum Part 1: designing a concept-based curriculum. Assess Technol Inst 2017;2.

29 Christmals Christmal D, Armstrong S. The development of advanced practice nursing (child health nurse practitioner) curriculum framework for Sub-Saharan Africa: a scoping review. In: first biennial conference. 24. Lobamba, Swaziland: Chi Xi at-Large Chapter,Honour Society of Nursing, 2017. http://chixiatlarge. com/wp-content/uploads/2017/06/Programme-Chi-Xi-at-LargeConference2017-FINAL-DRAFT.pdf

30 Giddens JF, Wright M, Gray I. Selecting concepts for a conceptbased curriculum: application of a benchmark approach. J Nurs Educ 2012;51:511-5.

31 Nursing and Midwifery Board of Ireland. Advanced practice (nursing) standards and requirements Dublin, 2017. Available: https://www. nmbi.ie/NMBI/media/NMBI/Advanced-Practice-Nursing-Standardsand-Requirements-2017.pdf?ext=.pdf 
32 University of British Columbia. Master of Nursing-Nurse practitioner: course and structure. SCH. nursing. 1. Columbia: University $\mathrm{Br}, 2017$. https://nursing.ubc.ca/sites/nursing.ubc.ca/files/documents/C\% 26S_MN-NP.pdf

33 Royal college of nursing. Advanced nurse practitioners- an RCN guide to advanced nursing practice, advanced nurse practitioners and programme accreditation contents London, 2012.

34 Greveson K. Fundamental aspects of advanced nursing practice in the field of medical aesthetics. Journal of Aesthetic Nursing 2013;2:334-7.

35 Lee GA, Fitzgerald L. A clinical internship model for the nurse practitioner programme. Nurse Educ Pract 2008;8:397-404.
36 Caputi L. The concept-based curriculum: what's all the buzz about? 2014. Available: http://www.nmnec.org/uploads/FileLinks/9338 75ef41ef4474b4e844f09423bbef/Caputi__The_Concept_Based Curriculum.pdf [Accessed 2 Oct 2017].

37 Giddens JF. Concepts for nursing practice. 1st Edn. St. Louis: Elsevier, 2013.

38 French S. The benefits and challenges of modular higher education curricula Melbourne, 2015. Available: http://melbourne-cshe.unimelb. edu.au/_data/assets/pdf_file/0009/2302695/modular_higher_ education sfrench oct2015.pdf [Accessed 25 Jan 2018].

39 Department of Health. Strategic plan for nurse education, training and. Pretoria, 2013. Available: http://www.sanc.co.za/archive/ archive2013/linked_files/Strategic_Plan_for_Nurse_Education_ Training_and_Practice.pdf [Accessed 8 Sep 2018]. 